\title{
A source-independent empirical correction procedure for the fast mobility and engine exhaust particle sizers
}

\author{
Naomi Zimmerman, Cheol-Heon Jeong, Jonathan M. Wang, \\ Manuel Ramos, James S. Wallace, and Greg J. Evans
}

Version Post-print/Accepted Manuscript

\begin{abstract}
Citation Zimmerman, Naomi, et al. "A source-independent empirical correction (published version) procedure for the fast mobility and engine exhaust particle sizers." Atmospheric Environment 100 (2015): 178-184.

Doi: 10.1016/j.atmosenv.2014.10.054

Copyright/License

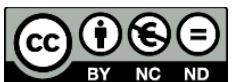
This work is licensed under the Creative Commons Attribution-NonCommercial-NoDerivatives 4.0 International License. To view a copy of this license, visit http://creativecommons.org/licenses/by-nc-nd/4.0/.
\end{abstract}

How to cite TSpace items

Always cite the published version, so the author(s) will receive recognition through services that track citation counts, e.g. Scopus. If you need to cite the page number of the author manuscript from TSpace because you cannot access the published version, then cite the TSpace version in addition to the published version using the permanent URI (handle) found on the record page.

This article was made openly accessible by $U$ of $T$ Faculty. Please tell us how this access benefits you. Your story matters. 
Corresponding author:

Professor Greg J. Evans.

Dept. of Chemical Engineering and Applied Chemistry

University of Toronto

200 College Street, Room 127, Toronto, Canada, M5S 3E5

Tel. 416-978-1821

Fax. 416-978-8605 


\section{HIGHLIGHTS}

- Accuracy of high-time resolution particle sizers is affected by particle morphology.

- These instruments also under-size particles larger than $80 \mathrm{~nm}$.

- We provide a source-independent correction protocol to address this issue.

- The correction protocol ensures agreement within $20 \%$ of a reference instrument.

\section{ABSTRACT}

The TSI Fast Mobility Particle Sizer (FMPS) and Engine Exhaust Particle Sizer (EEPS) provide size distributions for 6-560 $\mathrm{nm}$ particles with a time resolution suitable for characterizing transient particle sources; however, the accuracy of these instruments can be source dependent, due to influences of particle morphology. The aim of this study was to develop a sourceindependent correction protocol for the FMPS and EEPS. The correction protocol consists of (1) broadening the $>80 \mathrm{~nm}$ size range of the distribution to account for under-sizing by the FMPS and EEPS; (2) applying an existing correction protocol in the 8 to $93 \mathrm{~nm}$ size range; and (3) ambient air, diluted gasoline direct injection engine exhaust, and diluted diesel engine exhaust. Linear regression against a reference instrument, the Scanning Mobility Particle Sizer (SMPS), before and after applying the correction protocol demonstrated that the correction ensured agreement within $20 \%$.

\section{KEYWORDS}

EEPS; FMPS; SMPS; Morphology; Vehicle Emissions; Particle Size Distributions

\section{Introduction}

Shifting trends in particle-phase measurements of traffic-related air pollutants have produced a need for high time resolution $(\leq 1 \mathrm{~s})$ particle number and size characterization over a wide concentration range. For example, high time resolution instruments may be required to

60 characterize the performance of emission control technologies, such as diesel particulate filters

61 (Bergmann et al., 2009; Biswas et al., 2008; Kittelson et al., 2006; Zervas and Dorlhène, 2006);

62 the effect of fuel type on particle number concentrations during transient drive cycles (Liu et al., 
2007; Wang et al., 2006); or to characterize particulate matter (PM) in microenvironments near

64 roadways (Baldauf et al., 2008; Choi et al., 2013; Kozawa et al., 2009; Massoli et al., 2012;

65 Reponen et al., 2003; Zhu et al., 2002). Increasingly stringent emissions standards and the need

66 for real-world emission factors necessitate that the employed particle sizing and counting

67 instrumentation be accurate and precise; however, assessing accuracy is difficult due to the lack

68 of traceable measurement standards. These instruments are generally validated against auxiliary,

69 lower time resolution instrumentation, such as the TSI Scanning Mobility Particle Sizer (SMPS).

70 Two commonly applied instruments capable of high-time resolution particle number and size

71 characterization are the TSI Fast Mobility Particle Sizer (FMPS) and the Engine Exhaust Particle

72 Sizer (EEPS). When measuring traffic-related particle sources in parallel, agreement between the

73 SMPS the FMPS and the EEPS has been inconsistent (Asbach et al., 2009; Awasthi et al., 2013;

74 Kaminski et al., 2013; Leskinen et al., 2012).

In Zimmerman et al., (2014) it was established that measuring concentrations and size distributions of different particle sources with an FMPS or an EEPS; including ambient PM, laboratory-generated soot, aerosolized ionic solutions, and diesel PM; all required unique correction procedures based on linear regression with a Scanning Mobility Particle Sizer (SMPS). Differences in the correction procedures were largely attributed to particle morphology; particles with a more agglomerate structure required greater correction than those with a more spherical structure. Reliance on an additional particle sizer to correct for source-specific discrepancies is time consuming, dependent on the user having access to an SMPS, and limits the correction to particle sources that are constant over the SMPS measurement interval. Thus, the objective of this study was to develop an empirical correction protocol independent of PM source that is suitable for high-time resolution applications (i.e. independent of an SMPS). The sourceindependent correction procedure presented here involves an existing correction protocol developed in Jeong and Evans (2009), broadening the upper fraction of the size distribution, and a scaling factor from parallel measurement by an Ultrafine Water-based Condensation Particle Counter (UWCPC), which has the same time resolution as the FMPS. Application of this correction protocol ensures accuracy between an FMPS or EEPS and an SMPS within 20\%. If

93 Zimmerman et al. (2014), is required. 


\section{Methods}

\subsection{Particle Sizing Instruments}

Particle size distributions and number concentrations were obtained with an SMPS and either an FMPS or an EEPS. The EEPS (TSI model 3090) and FMPS (TSI model 3091) both function according to the same operating principles, measuring particle sizes from 6 to $560 \mathrm{~nm}$ using a series of electrometers; particles smaller than $8 \mathrm{~nm}$ and larger than $350 \mathrm{~nm}$ were excluded from analysis as concentrations were generally below detection. Operation of the EEPS and the FMPS used in this study has been previously described by Zimmerman et al. (2014). The SMPS used in this study consisted of an electrostatic classifier (TSI 3080), differential mobility analyzer (DMA) and ultrafine water-based condensation particle counter (UWCPC, TSI model 3786). Both the long-DMA (TSI 3081) and nano-DMA (TSI 3085) were included in the SMPS configuration. For the urban ambient measurements, an additional SMPS (TSI 3080 classifier) was used configured with the nano water-based ultrafine condensation particle counter $(\mathrm{N}$ WCPC, TSI model 3788) to allow for parallel measurements with the nano-DMA and longDMA; for the engine exhaust comparisons, the SMPS was equipped with the long-DMA for two replicates and the nano-DMA for the third replicate. The extended time scale ( 2 minutes, $100 \mathrm{~s}$ for scan up time $+20 \mathrm{~s}$ for scan retrace) required for a complete size distribution measurement limited the use of this instrument to steady-state testing. The SMPS used in this study has been previously described by Jeong and Evans (2009). For all parallel measurements, carbon filled conductive tubing was used to minimize particle line losses and sample lines to the instruments were identical in length (3 feet). Instrument flow rates were verified at the beginning of each experiment with a mass flow meter (TSI 4045) to ensure accuracy within $10 \%$ of the set point. As there is no particle counting measurement standard, auxiliary particle counting and sizing instrumentation (API 651 CPC, additional FMPS 3091) co-located at the Southern Ontario Centre for Atmospheric Aerosol Research (SOCAAR) Field Measurement Facility was used to verify agreement between instruments with the same working principle. A summary of the operating parameters and settings for the SMPS, EEPS and FMPS are provided in Table 1.

\subsection{Condensation Particle Counters}

In addition to the TSI 3786 UWCPC employed as a component of the SMPS configuration, two additional condensation particle counters (CPCs), a TSI 3788 Nano Water-Based CPC (N- 
WCPC) and Teledyne API 651 CPC, were used to measure total particle number concentration. These CPCs use water as their condensing fluid to grow particles for optical counting. A summary of the operating parameters and settings for the CPCs are provided in Table 1.

Table 1: Summary of Instrument Operation Settings and Software

\begin{tabular}{|c|c|c|c|c|c|}
\hline Instrument & TSI SMPS & TSI FMPS & TSI EEPS & TSI N-WCPC & API CPC \\
\hline Model & $\begin{array}{c}\text { Classifier: } 3080 \\
\text { DMA: } 3081 / 3085 \\
\text { CPC: } 3786\end{array}$ & 3091 & 3090 & 3788 & 651 \\
\hline $\begin{array}{c}\text { Aerostware } \\
\text { flow rate (LPM) }\end{array}$ & $\begin{array}{c}\text { Aerosol Instrument } \\
\text { Manager }\end{array}$ & $\begin{array}{c}\text { FMPS } \\
\text { Software } \\
\text { (ver. } 3.1 .0)\end{array}$ & $\begin{array}{c}\text { EEPS } \\
\text { Software } \\
\text { (ver. } 3.1 .1)\end{array}$ & $\begin{array}{c}\text { Aerosol } \\
\text { Instrument } \\
\text { Manager } \\
\text { (ver. } 9.0 .0)\end{array}$ & $\begin{array}{c}\text { Aerosol } \\
\text { Instrument } \\
\text { Manager } \\
\text { (ver. } 9.0 .0)\end{array}$ \\
\hline $\begin{array}{c}\text { Sheath air flow } \\
\text { rate (LPM) }\end{array}$ & 6.6 (CPC: 0.3) & 10.0 & 10.0 & 0.3 & 0.3 \\
\hline Time Resolution (s) & 1 CPC: 0.3$)$ & 40.0 & 40.0 & 0.3 & 0.3 \\
\hline Size Range & $\begin{array}{c}3085 \text { DMA: } 3-93 \mathrm{~nm} \\
3081 \text { DMA: } 12-340 \mathrm{~nm}\end{array}$ & $6-560 \mathrm{~nm}$ & $6-560 \mathrm{~nm}$ & $3 \mathrm{~nm}-3 \mu \mathrm{m}$ & $7 \mathrm{~nm}-3 \mu \mathrm{m}$ \\
\hline Notes & $\begin{array}{c}\text { TSI diffusion correction; } \\
1 \mu \mathrm{mimpactor}\end{array}$ & $1 \mu \mathrm{mimpactor}$ & $1 \mu \mathrm{mimpactor}$ & -- & - \\
\hline
\end{tabular}

\subsection{Particle Generation and Sampling}

132 Experiments were conducted with three particle classes: (1) laboratory-generated aerosols, (2)

133 urban ambient air, and (3) diluted heavy-duty diesel and light-duty gasoline direct injection

134 (GDI) engine exhaust (Figure 1).

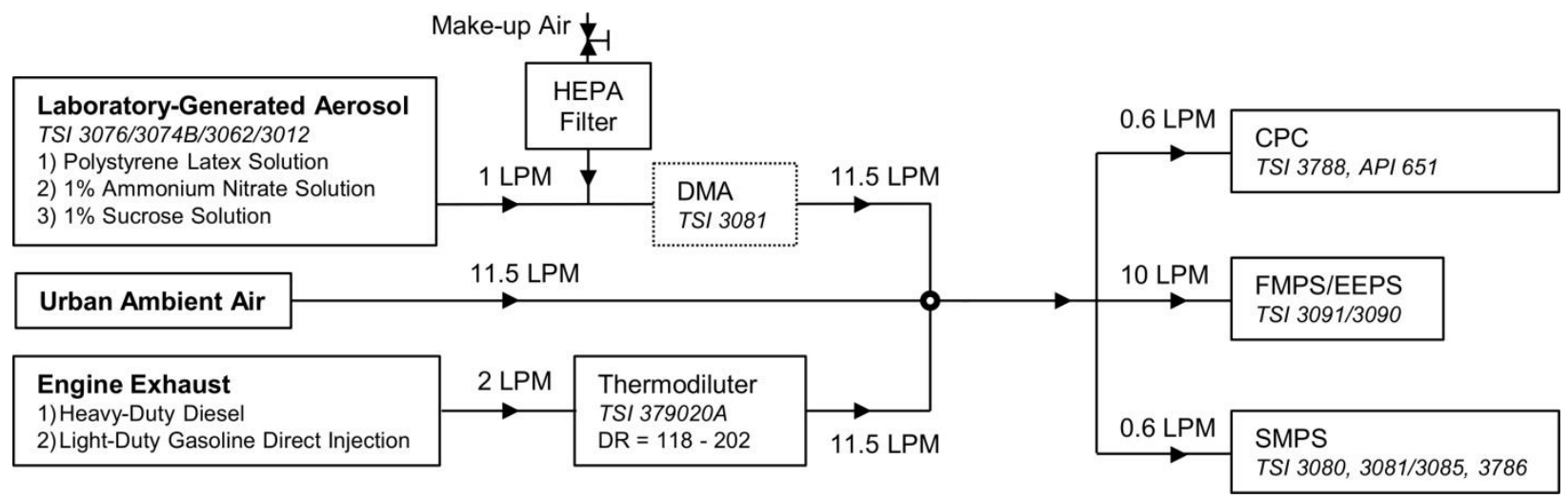

136 Figure 1: Process flow diagram of equivalency study experimental setup. Inter-comparisons were completed with three types of aerosol sources: (1) laboratory-generated aerosols, (2) urban ambient air, and (3) diluted heavy-duty diesel and light-duty gasoline direct injection engine exhaust. For the laboratory generated ammonium nitrate and sucrose aerosol, the DMA was used to generate a monodisperse sample. 
141 Aqueous $1 \% \mathrm{v} / \mathrm{v}$ solutions of ammonium nitrate $\left(\mathrm{NH}_{4} \mathrm{NO}_{3}\right)$ and sucrose were prepared using 142 deionized water and standard stock chemicals (sucrose: BioShop Canada, Burlington, ON, 143 Canada; $\mathrm{NH}_{4} \mathrm{NO}_{3}$ : Anachemia, Mississauga, $\mathrm{ON}$, Canada). Two polystyrene latex (PSL) aqueous 144 solutions (147 and $240 \mathrm{~nm}$ ) were prepared by mixing 3-5 drops of stock solution (NanoSphere ${ }^{\mathrm{TM}}$ 145 Size Standards, Thermo Scientific, Fremont, CA, USA) in $100 \mathrm{~mL}$ of deionized water and mixed 146 with a vortex mixer. The four aqueous solutions were aerosolized using a constant output 147 atomizer (TSI 3076) connected to a 20 psi filtered air supply (TSI 3074B). The generated aerosol 148 mixture was dried using a silica diffusion drier (TSI 3062) and neutralized in a $\mathrm{Kr}$ Aerosol 149 Neutralizer (TSI 3012) to remove any charge from the aerosol particles.

The atomizer aerosol measurements were conducted to evaluate previously observed 152 underestimations in particle size for the upper size range of the FMPS and EEPS (Jeong et al., 153 2010; Lee et al., 2013). Aerosolized ammonium nitrate $\left(\mathrm{NH}_{4} \mathrm{NO}_{3}\right)$ and sucrose was passed 154 through the long-DMA (TSI 3081) to produce monodisperse aerosol in the 80-300 nm size 155 range. The aerosolized PSL solutions were not passed through a DMA since PSL is a 156 monodisperse size calibration standard. The monodisperse aerosol was measured in parallel by 157 the SMPS, the N-WCPC, and either the EEPS or the FMPS. The 1 LPM aerosol flow produced 158 by the atomizer was supplemented with HEPA-filtered air to meet the sample flow requirements 159 of parallel FMPS/EEPS, SMPS and CPC operation. For each monodisperse aerosol, parallel 160 measurements were made for 10 minutes, yielding a total of 600 measurements by the N-WCPC 161 and the EEPS or FMPS, and 5 measurements by the SMPS. Flow constraints prevented parallel 162 operation of the EEPS and FMPS, thus the experiment was repeated for each.

164 The urban ambient air measurements were conducted at the Southern Ontario Centre for 165 Atmospheric Aerosol Research's Field Measurement Facility located in downtown Toronto, 166 Canada. Ambient air was sampled near the intersection of two high-trafficked roads. The 167 FMPS, two SMPSs, and API 651 CPC were operated in parallel over 5 consecutive days in 168 February 2014, yielding a total of 267,549 measurements by the FMPS and the API 651 and 1692860 measurements by the SMPS instruments. These measurements were conducted to validate 170 the correction protocol for a source where the total concentrations measured by the SMPS and 171 the FMPS or EEPS are in agreement. 
173 The engine exhaust comparisons were conducted with a heavy-duty diesel engine (1997 Tier 1

174 Cummins B3.9-C) and light-duty GDI engine exhaust (2012 Ford Focus) diluted by a TSI 175 Rotating Disk Thermodiluter. Neither engine was fitted with exhaust aftertreatment; all 176 measurements were taken from engine-out exhaust. The diesel engine was operated at steady177 state ISO8178 Mode 9 engine operation (1400 rpm, $105 \mathrm{~N}-\mathrm{m}$ ), which is representative of a low178 load intermediate speed, urban cruising driving condition. The GDI engine was operated at a 179 steady-state highway cruise condition (2600 rpm, $41.5 \mathrm{ft}-\mathrm{lb})$ representative of highway driving at 180 approximately $100 \mathrm{~km} / \mathrm{h}$. Six dilution ratios, ranging from 118 to 202, were tested for 10 minutes

181 each, generating a total of 3600 measurements by the EEPS and N-WCPC and 30 measurements 182 by the SMPS. Experiments conducted were performed in triplicate; two with the long-DMA and 183 one with the nano-DMA equipped on the SMPS. These measurements were conducted to 184 validate the correction protocol for a source where the total concentrations measured by the 185 SMPS and the FMPS or EEPS are in disagreement due to the agglomerate morphology of engine 186 exhaust PM.

\section{Results and Discussion}

\section{$189 \quad 3.1 \quad$ Laboratory-generated aerosol: broadening the upper size range}

190 For the PSL solutions (147 and $240 \mathrm{~nm}$ ) and each of the DMA-selected $\mathrm{NH}_{4} \mathrm{NO}_{3}$ and sucrose 191 aerosols $(80,90,100,150,200$, and $300 \mathrm{~nm})$, the number size distribution mode diameter was 192 determined for the SMPS, FMPS, and EEPS. The measured mode diameter was then compared 193 to the predicted mode diameter, which was either the DMA-selected particle size or the specified 194 PSL diameter (Figure 2). The $1 \% \mathrm{NH}_{4} \mathrm{NO}_{3}$ solution was excluded for the EEPS due to 195 concentrations being below instrument detection limits. Assessment of size-segregated particles 196 larger than $300 \mathrm{~nm}$ was not possible due to the large gap between size bins in the upper size 197 range and the low concentrations generated by the aerosol atomizer. 


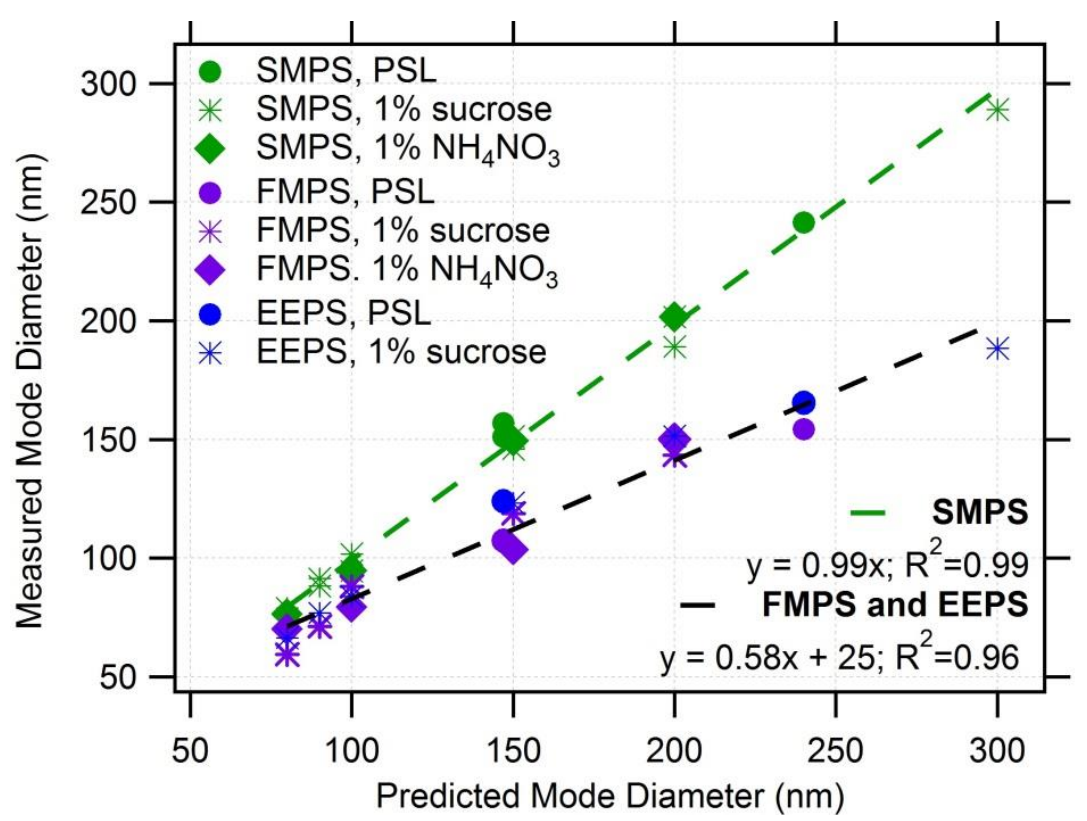

Figure 2: Measured SMPS, FMPS, and EEPS number size distribution mode diameter versus the predicted mode diameter from two PSL solutions (147 and $240 \mathrm{~nm}$ ) and DMA-selected atomized aerosol solutions of $\mathrm{NH}_{4} \mathrm{NO}_{3}$ and sucrose. A linear least squares regression fit for the SMPS and combined EEPS and FMPS measurements is also shown.

In general, for all particle sources tested, the number size distribution mode diameter measured by the SMPS agreed with the predicted mode diameter (slope $=0.99, \mathrm{R}^{2}=0.99$ ). In contrast, it was observed that both the FMPS and the EEPS undersized particles larger than $80 \mathrm{~nm}$. A least squares regression fit of the combined FMPS and EEPS measurements provided a relationship between the measured and predicted mode diameters to correct for this discrepancy. In Lee et al. (2013), a similar relationship was observed based on parallel measurement of DMA-selected atomized inorganic aerosols. This relationship was used to adjust the size bins for the FMPS and

Table 2: Original and adjusted size bins for the FMPS and the EEPS to correct for under-sizing in the $>80 \mathrm{~nm}$ size fraction based on calibration with laboratory-generated aerosol (see Figure 2). Adjusted Size Bin $=($ Original Size Bin - 25) / 0.58. Uncertainty is calculated based on the standard deviations on the regression slope and intercept.

\begin{tabular}{|c|c|}
\hline Original Size Bin Midpoint (nm) & Adjusted Size Bin Midpoint (nm) \\
\hline 80.6 & $92 \pm 13$ \\
\hline 93.1 & $114 \pm 14$ \\
\hline 107.5 & $139 \pm 15$ \\
\hline 124.1 & $168 \pm 17$ \\
\hline 143.3 & $201 \pm 18$ \\
\hline 165.5 & $239 \pm 20$ \\
\hline 191.1 & $283 \pm 22$ \\
\hline 220.7 & $334 \pm 25$ \\
\hline
\end{tabular}




\begin{tabular}{|l|c|}
\hline 254.8 & $393 \pm 28$ \\
\hline 294.3 & $462 \pm 31$ \\
\hline 339.8 & $540 \pm 35$ \\
\hline 392.4 & $631 \pm 40$ \\
\hline 453.2 & $736 \pm 45$ \\
\hline 523.3 & $857 \pm 51$ \\
\hline
\end{tabular}

217 Adjusting the size bins to the values presented in Table 2 effectively broadens the distribution in 218 the upper size region. This adjustment is particularly important if the number size distribution is 219 converted to a volume or mass size distribution where the particle radius is cubed. The 220 effectiveness of this correction was assessed for three additional particle sources: urban ambient 221 air (Figure 3A), diluted GDI engine exhaust (Figure 3B), and diluted heavy-duty diesel engine 222 exhaust (Figure 3C). In Figure 3, by visual inspection it was observed that adjusting the size bins 223 based on the correction presented in Table 2 improves the agreement of the upper distribution 224 measured by the FMPS or EEPS with that from the SMPS; however, in the cases of diluted GDI 225 engine exhaust (B) and diluted heavy-duty diesel exhaust (C) substantial overestimation in the sub-200 nm size range remains. This suggests that this correction alone is insufficient, and that further correction is needed to compensate for the effect of particle morphology as discussed in Section 3.2.

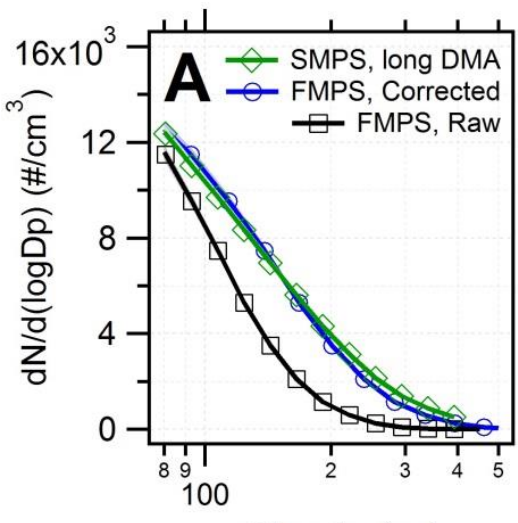

Diameter $(\mathrm{nm})$

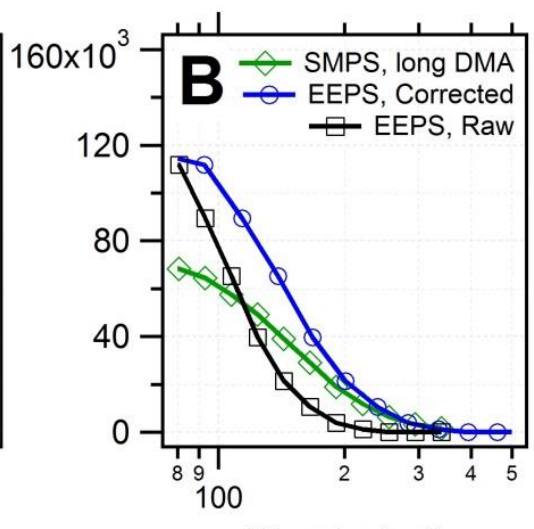

Diameter $(\mathrm{nm})$

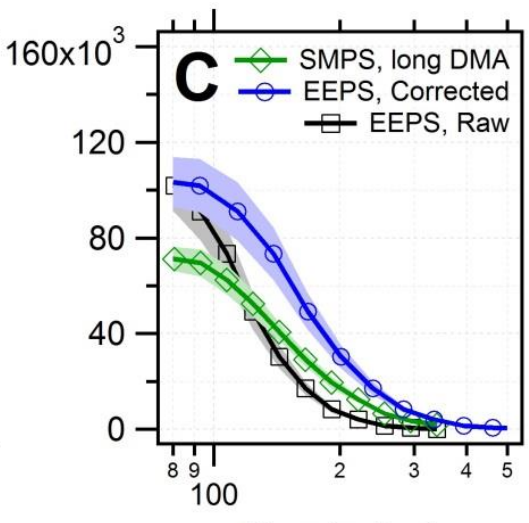

Diameter $(\mathrm{nm})$

230 Figure 3: Particle size distributions of the 80-500 nm size range of urban ambient aerosol (A), diluted GDI engine 231 exhaust $(B$, dilution ratio $=156)$, and diluted heavy-duty diesel engine exhaust $(C$, dilution ratio $=156)$ comparing 232 an SMPS equipped with a long DMA (3081) to either an FMPS or an EEPS before and after the correction provided 233 in Table 2. Shading represents the standard deviation.

\subsection{Development and validation of a source-independent correction protocol}


237 In Jeong and Evans (2009), an equivalence study compared an FMPS and an SMPS operated 238 with a nano-DMA and a UWCPC when measuring urban ambient air in downtown Toronto, 239 Canada. The authors noted size-specific distortions in the number concentrations measured by 240 the FMPS for sub-100 nm particles. These deviations were hypothesized to be the result of 241 limitations within the FMPS's data inversion algorithm in scenarios involving variable charging 242 efficiency and multiple charging of smaller particles. To compensate for these discrepancies, 243 correction factors for the 8 to $93 \mathrm{~nm}$ size range were developed using a linear regression analysis 244 that fit the FMPS measurements against size-segregated UWCPC measurements (Table 3). 245 Subsequently, in Zimmerman et al. (2014), it was established that application of this correction 246 factor can be extended to the EEPS when measuring urban ambient air, but that this existing 247 correction factor does not resolve the observed narrower distributions and higher total particle 248 concentrations compared to the SMPS for diluted diesel engine exhaust under ISO8178 Mode 9 249 operation. Higher total particle concentrations were attributed to the agglomerate morphology of 250 diesel particulate matter produced under load; comparisons of total concentrations measured by a 251 UWCPC and the FMPS for spherical and fractal particles produced by a miniCAST soot 252 generator (model 6200) confirmed this. Further discussion on the influence of particle 253 morphology on FMPS and EEPS accuracy is provided in Section 3.3 of Zimmerman et al. 254 (2014).

255 Table 3: Linear regression coefficients* $\left(b_{1}\right)$ and constants $\left(b_{0}\right)$ developed in Jeong and Evans, (2009) to correct the 256 size-resolved particle numbers measured by the FMPS or EEPS

\begin{tabular}{|c|c|c|}
\hline Size Bin Midpoint (nm) & $\mathrm{b}_{1}$ & $\mathrm{~b}_{0}$ \\
\hline 8.06 & 1.362 & 144 \\
\hline 9.31 & 0.820 & 19 \\
\hline 10.8 & 0.835 & 44 \\
\hline 12.4 & 1.139 & 103 \\
\hline 14.3 & 1.294 & 205 \\
\hline 16.5 & 1.227 & 443 \\
\hline 19.1 & 1.193 & 816 \\
\hline 22.1 & 1.215 & 1324 \\
\hline 25.5 & 1.134 & 1070 \\
\hline 29.4 & 0.951 & 624 \\
\hline 34.0 & 0.885 & 463 \\
\hline 39.2 & 0.935 & 258 \\
\hline 45.3 & 0.924 & 266 \\
\hline 52.3 & 0.928 & 240 \\
\hline 60.4 & 0.904 & 278 \\
\hline 69.8 & 0.913 & 126 \\
\hline 80.6 & 0.930 & 86 \\
\hline 93.1 & 0.936 & 108 \\
\hline
\end{tabular}


258 Accordingly, particle sizing and counting issues observed for the FMPS and the EEPS can be 259 generalized into three components: (1) size-specific distortions in the 8 to $93 \mathrm{~nm}$ size region as 260 described in Jeong and Evans (2009); (2) under-sizing of particles in the >80 nm size region, 261 discussed in Section 3.1; and (3) over-counting of particle number if the particle source contains 262 agglomerates. To address the issue of over-counting agglomerate particles, here we propose that 263 the ratio of total number concentration measured by an FMPS or an EEPS to the total number 264 concentration measured by a UWCPC or an N-WCPC be used as scaling factor. This ratio might 265 also serve as a useful surrogate indicator of particle morphology, although this is not covered 266 further here.

268 It has been previously observed that particle number concentration may be overestimated by the 269 FMPS or EEPS when particles are non-spherical, which affects the electrical charge inversion 270 algorithm; or when agglomerates form, which promotes multiple charging of particles (Kaminski 271 et al., 2013; Shin et al., 2010). These factors do not influence the counting efficiency of CPCs, 272 which use optical counting methods, thus scaling by the ratio of total concentration may 273 reasonably account for these effects. Additionally, butanol-based CPCs meet the Particle 274 Measurement Programme (PMP) requirements for Euro 5 and 6 vehicle exhaust particle number 275 emission legislation, and have been assessed in detail in Giechaskiel et al., 2009. While this 276 study employed water-based CPCs, it has been observed that there is acceptable agreement 277 between water and butanol-based CPCs for diesel combustion, urban ambient air, freeway 278 tunnel, and laboratory-generated particles (Biswas et al., 2005; Franklin et al., 2010; Iida et al., 279 2008; Kupc et al., 2013).

281 The application of this single scaling factor across all the particle sizes is an approximation, as 282 the particle morphology likely differs for different particle sizes. The scaling factor is 283 representative of the morphology of the predominant particles, but not necessarily of that of 284 particles in other size ranges. For example, smaller particles are likely single spherules even for 285 soot, and thus close to spherical. Accordingly, this scaling could in theory result in slight 286 underestimation of the number concentration of small particles for sources where the 287 predominant particles are larger agglomerates (e.g. diesel exhaust). However, this potential error 
was barely evident in the final corrected data for particles from different sources (Figure 5); it appears that it was negated by the other corrections applied to the small particles.

To assess the impact of the CPC-based scaling factor, this correction was combined with the 292 corrections discussed previously to produce a source-independent correction protocol, 293 summarized in Figure 4. A step-by-step example of applying the empirical correction factor is 294 provided in the Supplemental Information.

\subsection{6 to $93.1 \mathrm{~nm}$ size bins:}

Apply established correction factor

(Jeong and Evans, 2009) provided in Table 3

$$
\text { Corrected }=b_{1}(\text { Raw })+b_{0}
$$

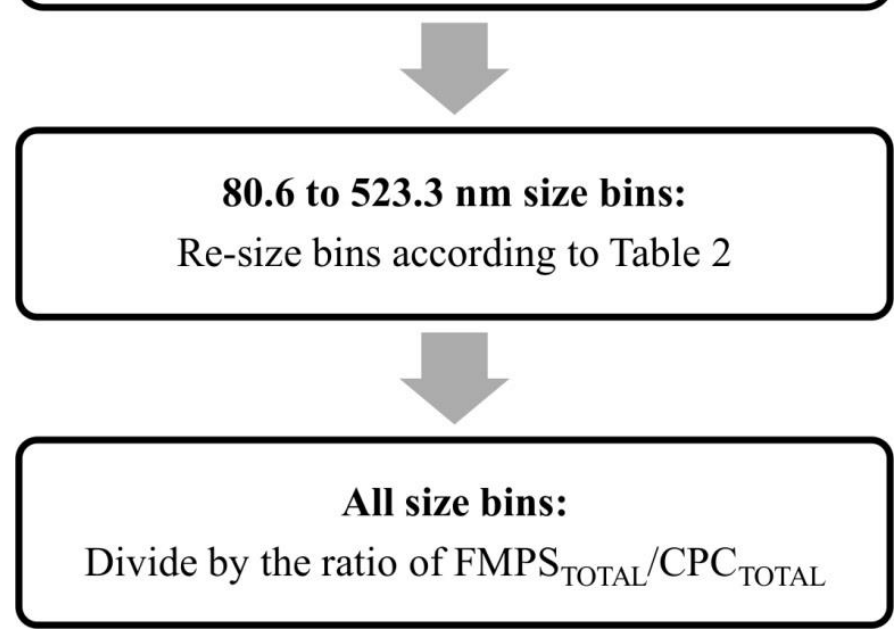

Figure 4: Summary of the empirical correction protocol. Dividing by the ratio of total number concentration measured by the FMPS and the CPC should be done at the highest possible time resolution, i.e. 1 second.

To assess the efficacy of the proposed correction protocol, average number concentration size distributions produced by the FMPS or the EEPS before and after correction were compared to the SMPS for three particle sources: (1) urban ambient air, source A (Figure 5-A1); (2) diluted GDI engine exhaust, source B (Figure 5-B1); and (3) diluted heavy-duty diesel engine exhaust, source $\mathrm{C}$ (Figure 5-C1). A summary of the total number concentration ranges measured by the FMPS or EEPS, SMPS, and CPC and ratios of total number concentration for the three particle sources used to evaluate the effectiveness of the empirical correction protocol is provided in Table 4. 
Raw and corrected number concentrations were then averaged to a two minute time scale and

310 linear regression between the FMPS or EEPS and the SMPS of size bins in the $<100 \mathrm{~nm}$ size

311 range was conducted (Figure 5-A2, 5-B2, 5-C2). An orthogonal distance regression method was

312 used, as this method is better suited to handle observation errors in both the independent and

313 dependent variables, unlike the ordinary least squares approach (Boggs et al., 1987). The particle

314 source dictated the SMPS-DMA configuration used for linear regression: the nano-DMA for the

315 urban ambient air, and the long-DMA for the diluted engine exhaust. Linear regression was

316 limited to the $<100 \mathrm{~nm}$ size range since larger size bins in the FMPS/EEPS and SMPS are no

317 longer aligned following the adjustment provided in Section 3.1, Table 2; however, visual

318 inspection (Figure 5) indicated good agreement across this upper size range for all three particle

319 sources and showed improvements in agreement for the diluted GDI and diesel engine exhaust

320 particle sources as compared to Figure 3.

321 Table 3: Summary of total number concentration ranges and ratios of total number concentration for the three 322 particle sources used to evaluate the effectiveness of the empirical correction protocol.

\begin{tabular}{|c|c|c|c|c|}
\hline \multirow[b]{2}{*}{ Particle Source } & \multirow{2}{*}{$\begin{array}{c}\text { FMPSTOTAL/CPCTOTAL } \\
\text { or } \\
\text { EEPSTOTAL/CPCTOTAL }^{\text {Thet }}\end{array}$} & \multicolumn{3}{|c|}{ Total Number Concentration Range $\left(\# / \mathrm{cm}^{3}\right)$} \\
\hline & & FMPS or EEPS & $C P C$ & SMPS \\
\hline $\begin{array}{l}\text { A: Urban } \\
\text { ambient air }\end{array}$ & $1.1 \pm 0.21$ & $\begin{array}{l}\text { Min: } 2.9 \times 10^{3} \\
\operatorname{Max}: 2.5 \times 10^{5}\end{array}$ & $\begin{array}{l}\text { Min: } 3.4 \times 10^{3} \\
\operatorname{Max}: 2.5 \times 10^{5}\end{array}$ & $\begin{array}{l}\text { Min: } 3.9 \times 10^{3} \\
\text { Max: } 1.9 \times 10^{5}\end{array}$ \\
\hline $\begin{array}{l}\text { B: Diluted GDI } \\
\text { exhaust }\end{array}$ & $1.37 \pm 0.06$ & $\begin{array}{l}\text { Min: } 2.6 \times 10^{4} \\
\operatorname{Max}: 1.7 \times 10^{5}\end{array}$ & $\begin{array}{l}\text { Min: } 2.0 \times 10^{4} \\
\text { Max: } 7.8 \times 10^{4}\end{array}$ & $\begin{array}{l}\text { Min: } 2.1 \times 10^{4} \\
\text { Max: } 7.0 \times 10^{4}\end{array}$ \\
\hline $\begin{array}{l}\text { C: Diluted } \\
\text { diesel exhaust }\end{array}$ & $1.47 \pm 0.16$ & $\begin{array}{l}\text { Min: } 5.7 \times 10^{4} \\
\text { Max: } 1.6 \times 10^{5}\end{array}$ & $\begin{array}{l}\text { Min: } 4.2 \times 10^{4} \\
\operatorname{Max}: 9.8 \times 10^{5}\end{array}$ & $\begin{array}{l}\text { Min: } 5.2 \times 10^{4} \\
\operatorname{Max}: 1.1 \times 10^{5}\end{array}$ \\
\hline
\end{tabular}



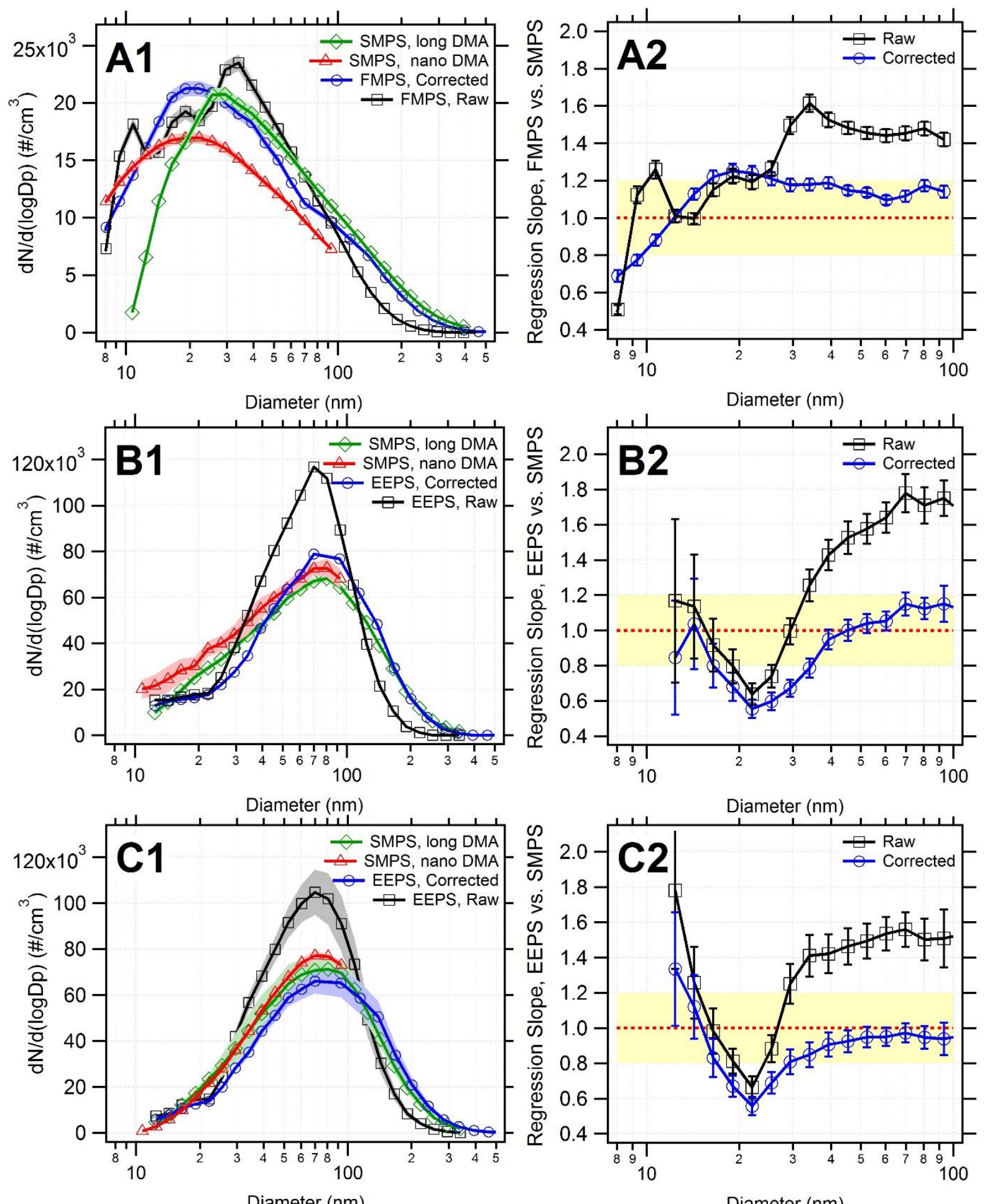

Diameter (nm)

Diameter (nm)

Figure 5: Particle size distributions (A1, B1, C1) and linear regression slopes of the reference instrument (SMPS) vs. either the FMPS or the EEPS (A2, B2, C2) before and after correction with the empirical correction protocol. A1 and $\mathrm{A} 2$ are from urban ambient aerosol, B1 and B2 are from diluted GDI exhaust, and C1 and C2 are from diluted diesel exhaust (dilution ratio $=156$ ). Shading in column 1 represents a 95\% confidence interval (urban ambient aerosol, A1) or the standard deviation (GDI, B1; diesel, C1), the error bars shown in A2, B2, and C2 represent three times the standard error of the regression slope. 
In Figure 5, it was observed that for all three particle sources tested, the empirical correction protocol generally improved agreement between the FMPS, or the EEPS, and the SMPS to within $20 \%$. For the urban ambient air, in Figure 5-A1 it was observed that following correction, the FMPS number concentrations exceeded those measured by the SMPS configured with the nano-DMA; however, in Figure 5-A2 this difference was determined to be within the $20 \%$ tolerance limits of the correction protocol. It was also observed that the SMPS configured with the long-DMA measured significantly lower concentrations in the sub-25 $\mathrm{nm}$ size region compared to both the FMPS and the SMPS configured with the nano-DMA. This is hypothesized to be a result of large diffusional losses in the longer DMA column, thus potentially indicating that the TSI diffusion correction is not well-suited to the long-DMA, which is an area for future investigation. Comparing the shape of the FMPS size distribution before and after correction, the correction protocol corrects for the tri-modal size distribution and the upper tail shows improved agreement with the long-DMA configured SMPS.

For the diluted GDI (Figure 5-B1 and 5-B2) and heavy-duty diesel (Figure 5-C1 and 5-C2) exhaust, the empirical correction, significantly improved the agreement in the $>30 \mathrm{~nm}$ size region with the SMPS equipped with either the nano-DMA or long-DMA. In the sub-30 nm size range, the correction protocol made no statistically significant impact except for the $29 \mathrm{~nm}$ and $25 \mathrm{~nm}$ size bins for the GDI and diesel, respectively, where the correction protocol resulted in regression slopes that diverged farther from unity as compared to the uncorrected distribution. Disagreements between the EEPS and the SMPS in the sub-30 nm size range are likely attributable to the low particle concentrations and higher detection limits for the EEPS in this 353 size range.

The need for the correction protocol presented in this study may be due to limitations in the FMPS and EEPS data inversion algorithms and how these algorithms account for multiple charging of non-spherical particles (Kaminski et al., 2013; Shin et al., 2010). The ideal method to ensure accurate measurements with minimal post-processing would be improvements to the data inversion algorithm; however, the empirical correction protocol presented here represents a 360 viable alternative if instrument agreement within $20 \%$ is suitable for the application. If more 
precise agreement is needed, source-specific data correction based on linear regression against an

362 SMPS is recommended.

363

\section{Conclusions}

365 In this study, a source-independent empirical correction protocol was developed for the FMPS and EEPS that ensured agreement within 20\% against a reference SMPS. This study was undertaken to address the under-sizing and over-counting issues established previously when measuring non-spherical particles. The correction protocol consists of (1) broadening the $>80 \mathrm{~nm}$ size range of the distribution to account for under-sizing by the FMPS and EEPS; (2) applying an existing correction protocol in the 8 to $93 \mathrm{~nm}$ size range; and (3) dividing each size bin by the ratio of total concentration measured by the FMPS or EEPS and a water-based Condensation

372 Particle Counter (CPC). Scaling the size distribution by the total concentration ratio should be

373 done at the highest possible time resolution (i.e. 1 second); however, for steady state systems 374 where this ratio is well-characterized, it is possible to apply one consistent FMPS or EEPS to 375 CPC ratio.

The efficacy of the correction protocol was assessed for three sources: urban ambient air, diluted gasoline direct injection exhaust, and diluted diesel exhaust. Orthogonal distance linear regression against the SMPS of comparable size bins before and after applying the correction protocol demonstrated that the correction ensured agreement within 20\%. Improvements to the shape of the particle number size distribution after correction was also observed. If more precise agreement is needed, it is recommended that prior to operation of the FMPS or EEPS when measuring agglomerates, such as those produced in vehicle emission tests or near-road measurement of traffic-related air pollutants, correction factors are established based on parallel SMPS measurements to ensure equivalency.

\section{ACKNOWLEDGEMENTS}

388 Funding this study was provided by the Canadian Foundation for Innovation and the Natural 389 Sciences and Engineering Research Council (NSERC) Strategic Project Grant program. N. 390 Zimmerman's funding was provided by the NSERC Postgraduate Scholarship. 


\section{REFERENCES}

Asbach, C., Kaminski, H., Fissan, H., Monz, C., Dahmann, D., Mülhopt, S., Paur, H.R., Kiesling, H.J., Herrmann, F., Voetz, M., Kuhlbusch, T. a. J., 2009. Comparison of four mobility particle sizers with different time resolution for stationary exposure measurements. J. Nanoparticle Res. 11, 1593-1609.

Awasthi, A., Wu, B.-S., Liu, C.-N., Chen, C.-W., Uang, S.-N., Tsai, C.-J., 2013. The Effect of Nanoparticle Morphology on the Measurement Accuracy of Mobility Particle Sizers. Mapan 28, 205-215.

Baldauf, R., Thoma, E., Hays, M., Shores, R., Kinsey, J., Gullett, B., Kimbrough, S., Isakov, V., Long, T., Snow, R., Khlystov, A., Weinstein, J., Chen, F.-L., Seila, R., Olson, D., Gilmour, I., Cho, S.-H., Watkins, N., Rowley, P., Bang, J., 2008. Traffic and Meteorological Impacts on Near-Road Air Quality: Summary of Methods and Trends from the Raleigh Near-Road Study. J. Air Waste Manage. Assoc. 58, 865-878.

Bergmann, M., Kirchner, U., Vogt, R., Benter, T., 2009. On-road and laboratory investigation of low-level PM emissions of a modern diesel particulate filter equipped diesel passenger car. Atmos. Environ. 43, 1908-1916.

Biswas, S., Fine, P.M., Geller, M.D., Hering, S. V., Sioutas, C., 2005. Performance Evaluation of a Recently Developed Water-Based Condensation Particle Counter. Aerosol Sci. Technol. 39, 419-427.

Biswas, S., Hu, S., Verma, V., Herner, J.D., Robertson, W.H., Ayala, A., Sioutas, C., 2008. Physical properties of particulate matter (PM) from late model heavy-duty diesel vehicles operating with advanced PM and NOx emission control technologies. Atmos. Environ. 42, 5622-5634.

Boggs, P.T., Byrd, R.H., Schnabel, R.B., 1987. A Stable and Efficient Algorithm for Nonlinear Orthogonal Distance Regression. SIAM J. Sci. Stat. Comput. 8, 1052-1078.

Choi, W., Hu, S., He, M., Kozawa, K., Mara, S., Winer, A.M., Paulson, S.E., 2013. Neighborhood-scale air quality impacts of emissions from motor vehicles and aircraft. Atmos. Environ. 80, 310-321.

Franklin, L.M., Bika, A.S., Watts, W.F., Kittelson, D.B., 2010. Comparison of Water and Butanol Based CPCs for Examining Diesel Combustion Aerosols. Aerosol Sci. Technol. 44, 629-638.

Giechaskiel, B., Wang, X., Horn, H.-G., Spielvogel, J., Gerhart, C., Southgate, J., Jing, L., Kasper, M., Drossinos, Y., Krasenbrink, A., 2009. Calibration of Condensation Particle Counters for Legislated Vehicle Number Emission Measurements. Aerosol Sci. Technol. 43, 1164-1173.

lida, K., Stolzenburg, M.R., McMurry, P.H., Smith, J.N., Quant, F.R., Oberreit, D.R., Keady, P.B., EigurenFernandez, A., Lewis, G.S., Kreisberg, N.M., Hering, S. V., 2008. An Ultrafine, Water-Based Condensation Particle Counter and its Evaluation under Field Conditions. Aerosol Sci. Technol. 42, 862-871.

Jeong, C.-H., Evans, G.J., 2009. Inter-Comparison of a Fast Mobility Particle Sizer and a Scanning Mobility Particle Sizer Incorporating an Ultrafine Water-Based Condensation Particle Counter. Aerosol Sci. Technol. 43, 364373.

Jeong, C.-H., Evans, G.J., McGuire, M.L., Chang, R.Y.-W., Abbatt, J.P.D., Zeromskiene, K., Mozurkewich, M., Li, S.-M., Leaitch, W.R., 2010. Particle formation and growth at five rural and urban sites. Atmos. Chem. Phys. 10, 7979-7995.

Kaminski, H., Kuhlbusch, T. a. J., Rath, S., Götz, U., Sprenger, M., Wels, D., Polloczek, J., Bachmann, V., Dziurowitz, N., Kiesling, H.-J., Schwiegelshohn, A., Monz, C., Dahmann, D., Asbach, C., 2013. Comparability of mobility particle sizers and diffusion chargers. J. Aerosol Sci. 57, 156-178. 
Kittelson, D.B., Watts, W.F., Johnson, J.P., Rowntree, C., Payne, M., Goodier, S., Warrens, C., Preston, H., Zink, U., Ortiz, M., Goersmann, C., Twigg, M.V., Walker, A.P., Caldow, R., 2006. On-road evaluation of two Diesel exhaust aftertreatment devices. J. Aerosol Sci. 37, 1140-1151.

Kozawa, K.H., Fruin, S.A., Winer, A.M., 2009. Near-road air pollution impacts of goods movement in communities adjacent to the Ports of Los Angeles and Long Beach. Atmos. Environ. 43, 2960-2970.

Kupc, A., Bischof, O., Tritscher, T., Beeston, M., Krinke, T., Wagner, P.E., 2013. Laboratory Characterization of a New Nano-Water-Based CPC 3788 and Performance Comparison to an Ultrafine Butanol-Based CPC 3776. Aerosol Sci. Technol. 47, 183-191.

Lee, B.P., Li, Y.J., Flagan, R.C., Lo, C., Chan, C.K., 2013. Sizing Characterization of the Fast-Mobility Particle Sizer (FMPS) Against SMPS and HR-ToF-AMS. Aerosol Sci. Technol. 47, 1030-1037.

Leskinen, J., Joutsensaari, J., Lyyränen, J., Koivisto, J., Ruusunen, J., Järvelä, M., Tuomi, T., Hämeri, K., Auvinen, A., Jokiniemi, J., 2012. Comparison of nanoparticle measurement instruments for occupational health applications. J. Nanoparticle Res. 14, 718.

Liu, Z.G., Vasys, V.N., Kittelson, D.B., 2007. Nuclei-Mode Particulate Emissions and Their Response to Fuel Sulfur Content and Primary Dilution during Transient Operations of Old and Modern Diesel Engines. Environ. Sci. Technol. 41, 6479-83.

Massoli, P., Fortner, E.C., Canagaratna, M.R., Williams, L.R., Zhang, Q., Sun, Y., Schwab, J.J., Trimborn, A., Onasch, T.B., Demerjian, K.L., Kolb, C.E., Worsnop, D.R., Jayne, J.T., 2012. Pollution Gradients and Chemical Characterization of Particulate Matter from Vehicular Traffic near Major Roadways: Results from the 2009 Queens College Air Quality Study in NYC. Aerosol Sci. Technol. 46, 1201-1218.

Reponen, T., Grinshpun, S. a., Trakumas, S., Martuzevicius, D., Wang, Z.-M., LeMasters, G., Lockey, J.E., Biswas, P., 2003. Concentration gradient patterns of aerosol particles near interstate highways in the Greater Cincinnati airshed. J. Environ. Monit. 5, 557.

Shin, W.G., Wang, J., Mertler, M., Sachweh, B., Fissan, H., Pui, D.Y.H., 2010. The effect of particle morphology on unipolar diffusion charging of nanoparticle agglomerates in the transition regime. J. Aerosol Sci. 41, 975-986.

Wang, J., Storey, J., Domingo, N., Huff, S., Thomas, J., West, B., 2006. Studies of Diesel Engine Particle Emissions During Transient Operations Using an Engine Exhaust Particle Sizer. Aerosol Sci. Technol. 40, 1002-1015.

Zervas, E., Dorlhène, P., 2006. Comparison of Exhaust Particle Number Measured by EEPS, CPC, and ELPI. Aerosol Sci. Technol. 40, 977-984.

Zhu, Y., Hinds, W.C., Kim, S., Shen, S., Sioutas, C., 2002. Study of ultrafine particles near a major highway with heavy-duty diesel traffic. Atmos. Environ. 36, 4323-4335.

Zimmerman, N., Godri Pollitt, K.J., Jeong, C.-H., Wang, J.M., Jung, T., Cooper, J.M., Wallace, J.S., Evans, G.J., 2014. Comparison of three nanoparticle sizing instruments: The influence of particle morphology. Atmos. Environ. 86, 140-147. 
467 Table 1: Summary of Instrument Operation Settings and Software

\begin{tabular}{|c|c|c|c|c|c|}
\hline Instrument & TSI SMPS & TSI FMPS & TSI EEPS & $T S I N-W C P C$ & $A P I C P C$ \\
\hline Model & $\begin{array}{l}\text { Classifier: } 3080 \\
\text { DMA: } 3081 / 3085 \\
\text { CPC: } 3786\end{array}$ & 3091 & 3090 & 3788 & 651 \\
\hline Software & $\begin{array}{l}\text { Aerosol Instrument } \\
\text { Manager } \\
\text { (ver. 9.0.0) }\end{array}$ & $\begin{array}{c}\text { FMPS } \\
\text { Software } \\
\text { (ver. 3.1.0) }\end{array}$ & $\begin{array}{c}\text { EEPS } \\
\text { Software } \\
\text { (ver. 3.1.1) }\end{array}$ & $\begin{array}{c}\text { Aerosol } \\
\text { Instrument } \\
\text { Manager } \\
\text { (ver. 9.0.0) }\end{array}$ & $\begin{array}{l}\text { Aerosol } \\
\text { Instrument } \\
\text { Manager } \\
\text { (ver. 9.0.0) }\end{array}$ \\
\hline $\begin{array}{c}\text { Aerosol sample } \\
\text { flow rate (LPM) }\end{array}$ & 0.6 (CPC: 0.3$)$ & 10.0 & 10.0 & 0.3 & 0.3 \\
\hline $\begin{array}{c}\text { Sheath air flow } \\
\text { rate (LPM) }\end{array}$ & 6.0 (CPC: 0.3$)$ & 40.0 & 40.0 & 0.3 & 0.3 \\
\hline Time Resolution (s) & 120 & 1 & 0.1 & 1 & 1 \\
\hline Size Range & $\begin{array}{c}3085 \text { DMA: } 3-93 \mathrm{~nm} \\
\text { 3081 DMA: } 12-340 \mathrm{~nm}\end{array}$ & $6-560 \mathrm{~nm}$ & $6-560 \mathrm{~nm}$ & $3 \mathrm{~nm}-3 \mu \mathrm{m}$ & $7 \mathrm{~nm}-3 \mu \mathrm{m}$ \\
\hline Notes & $\begin{array}{l}\text { TSI diffusion correction; } \\
1 \mu \mathrm{mimpactor}\end{array}$ & $1 \mu \mathrm{m}$ impactor & $1 \mu \mathrm{m}$ impactor & -- & -- \\
\hline
\end{tabular}

Table 2: Original and adjusted size bins for the FMPS and the EEPS to correct for under-sizing in the $>80 \mathrm{~nm}$ size Bin - 25) / 0.58. Uncertainty is calculated based on the standard deviations on the regression slope and intercept.

\begin{tabular}{|c|c|}
\hline Original Size Bin Midpoint (nm) & Adjusted Size Bin Midpoint (nm) \\
\hline 80.6 & $92 \pm 13$ \\
\hline 93.1 & $114 \pm 14$ \\
\hline 107.5 & $139 \pm 15$ \\
\hline 124.1 & $168 \pm 17$ \\
\hline 143.3 & $201 \pm 18$ \\
\hline 165.5 & $239 \pm 20$ \\
\hline 191.1 & $283 \pm 22$ \\
\hline 220.7 & $334 \pm 25$ \\
\hline 254.8 & $393 \pm 28$ \\
\hline 294.3 & $462 \pm 31$ \\
\hline 339.8 & $540 \pm 35$ \\
\hline 392.4 & $631 \pm 40$ \\
\hline 453.2 & $736 \pm 45$ \\
\hline 523.3 & $857 \pm 51$ \\
\hline & \\
\hline
\end{tabular}

Table 3: Linear regression coefficients* $\left(b_{1}\right)$ and constants $\left(b_{0}\right)$ developed in Jeong and Evans, (2009) to correct the size-resolved particle numbers measured by the FMPS or EEPS

\begin{tabular}{|c|c|c|}
\hline Size Bin Midpoint $(\mathrm{nm})$ & $\mathrm{b}_{1}$ & $\mathrm{~b}_{0}$ \\
\hline 8.06 & 1.362 & 144 \\
\hline 9.31 & 0.820 & 19 \\
\hline 10.8 & 0.835 & 44 \\
\hline 12.4 & 1.139 & 103 \\
\hline 14.3 & 1.294 & 205 \\
\hline 16.5 & 1.227 & 443 \\
\hline 19.1 & 1.193 & 816 \\
\hline 22.1 & 1.215 & 1324 \\
\hline
\end{tabular}




\begin{tabular}{|c|c|c|}
\hline 25.5 & 1.134 & 1070 \\
\hline 29.4 & 0.951 & 624 \\
\hline 34.0 & 0.885 & 463 \\
\hline 39.2 & 0.935 & 258 \\
\hline 45.3 & 0.924 & 266 \\
\hline 52.3 & 0.928 & 240 \\
\hline 60.4 & 0.904 & 278 \\
\hline 69.8 & 0.913 & 126 \\
\hline 80.6 & 0.930 & 86 \\
\hline 93.1 & 0.936 & 108 \\
\hline * Corrected $=\mathrm{b}_{1}($ Raw $)+\mathrm{b}_{0}$ \\
\hline
\end{tabular}

475

476

477

478

Table 4: Summary of total number concentration ranges and ratios of total number concentration for the three particle sources used to evaluate the effectiveness of the empirical correction protocol.

\begin{tabular}{|c|c|c|c|c|}
\hline \multirow{2}{*}{ Particle Source } & \multirow{2}{*}{ 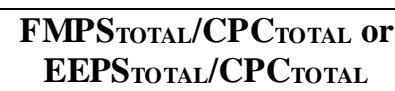 } & \multicolumn{3}{|c|}{ Total Number Concentration Range $\left(\# / \mathrm{cm}^{3}\right)$} \\
\hline & & FMPS or EEPS & $C P C$ & $S M P S$ \\
\hline $\begin{array}{l}\text { A: Urban ambient } \\
\text { air }\end{array}$ & $1.1 \pm 0.21$ & $\begin{array}{l}\text { Min: } 2.9 \times 10^{3} \\
\text { Max: } 2.5 \times 10^{5}\end{array}$ & $\begin{array}{l}\text { Min: } 3.4 \times 10^{3} \\
\text { Max: } 2.5 \times 10^{5}\end{array}$ & $\begin{array}{l}\text { Min: } 3.9 \times 10^{3} \\
\text { Max: } 1.9 \times 10^{5}\end{array}$ \\
\hline $\begin{array}{l}\text { B: Diluted GDI } \\
\text { exhaust }\end{array}$ & $1.37 \pm 0.06$ & $\begin{array}{l}\text { Min: } 2.6 \times 10^{4} \\
\text { Max: } 1.7 \times 10^{5}\end{array}$ & $\begin{array}{l}\text { Min: } 2.0 \times 10^{4} \\
\text { Max: } 7.8 \times 10^{4}\end{array}$ & $\begin{array}{l}\text { Min: } 2.1 \times 10^{4} \\
\text { Max: } 7.0 \times 10^{4}\end{array}$ \\
\hline $\begin{array}{l}\text { C: Diluted diesel } \\
\text { exhaust }\end{array}$ & $1.47 \pm 0.16$ & $\begin{array}{l}\text { Min: } 5.7 \times 10^{4} \\
\text { Max: } 1.6 \times 10^{5}\end{array}$ & $\begin{array}{l}\text { Min: } 4.2 \times 10^{4} \\
\text { Max: } 9.8 \times 10^{5}\end{array}$ & $\begin{array}{l}\text { Min: } 5.2 \times 10^{4} \\
\text { Max: } 1.1 \times 10^{5}\end{array}$ \\
\hline
\end{tabular}

\section{FIGURE CAPTIONS}

Figure 2: Process flow diagram of equivalency study experimental setup. Inter-comparisons were completed with three types of aerosol sources: (1) laboratory-generated aerosols, (2) urban ambient air, and (3) diluted heavy-duty diesel and light-duty gasoline direct injection engine exhaust. For the laboratory generated ammonium nitrate and sucrose aerosol, the DMA was used to generate a monodisperse sample.

Figure 2: Measured SMPS, FMPS, and EEPS number size distribution mode diameter versus the predicted mode diameter from two PSL solutions (147 and $240 \mathrm{~nm}$ ) and DMA-selected atomized aerosol solutions of $\mathrm{NH}_{4} \mathrm{NO}_{3}$ and sucrose. A linear least squares regression fit for the SMPS and combined EEPS and FMPS measurements is also shown.

Figure 3: Particle size distributions of the 80-500 nm size range of urban ambient aerosol (A), diluted GDI engine exhaust $(\mathrm{B}$, dilution ratio $=156)$, and diluted heavy-duty diesel engine exhaust $(\mathrm{C}$, dilution ratio $=156)$ comparing an SMPS equipped with a long DMA (3081) to either an FMPS or an EEPS before and after the correction provided in Table 2. Shading represents the standard deviation.

Figure 4: Summary of the empirical correction protocol. Dividing by the ratio of total number concentration measured by the FMPS and the CPC should be done at the highest possible time resolution, i.e. 1 second. 
501 Figure 5: Particle size distributions (A1, B1, C1) and linear regression slopes of the reference 502 instrument (SMPS) vs. either the FMPS or the EEPS (A2, B2, C2) before and after correction 503 with the empirical correction protocol. A1 and A2 are from urban ambient aerosol, B1 and B2 504 are from diluted GDI exhaust, and $\mathrm{C} 1$ and $\mathrm{C} 2$ are from diluted diesel exhaust (dilution ratio = 505 156). Shading in column 1 represents a 95\% confidence interval (urban ambient aerosol, A1) or 506 the standard deviation (GDI, B1; diesel, C1), the error bars shown in A2, B2, and C2 represent 507 three times the standard error of the regression slope.

508 